\title{
A STUDY OF QUALITY OF LIFE IN PATIENTS WITH HYPERTENSION
}

\author{
Aaina Malhotra ${ }^{1}$, Anuj Mahajan ${ }^{2}$, Tejinderpal Singh ${ }^{3}$, Anju Bhagtana ${ }^{4}$, Dinesh Sood ${ }^{5}$ \\ 1 Junior Resident, Department of Anaesthesia, DMCH, Ludhiana, Punjab. \\ ${ }^{2}$ Senior Resident, Department of Surgery, DMCH, Ludhiana, Punjab. \\ 3Senior Resident, Department of Surgery, Fortis, Ludhiana, Punjab. \\ ${ }^{4}$ Senior Resident, Department of Surgery, DMCH, Ludhiana, Punjab. \\ ${ }^{5}$ Professor, Department of Anaesthesia, DMCH, Ludhiana, Punjab.
}

BBSTRACT
QACKGROUND
related to health are increasingly being used to adjust measures of effectiveness for clinical decision making, resource allocation
and to evaluate drugs in clinical trials of hypertension.

\section{MATERIALS AND METHODS}

The Descriptive study was conducted on 50 patients attending the OPD of Cardiology Unit of a north Indian hospital for a period of 2 months. All patients in the age group of 18 - 60 years who were drug naïve were included.

\section{RESULTS}

Hypertension was common in the age group of 56 - 65 years, males. Most common antihypertensive drugs prescribed were betablockers, ARB's, ACEI's, Diuretics and CCB's. The maximum reduction in pulse rate was produced by beta blockers and diuretics; that in SBP with CCB's and ARB's and in DBP with CCB's, ARB's and beta blockers.

\section{CONCLUSION}

The use of antihypertensive drugs improved the QOL in $90 \%$ of study subjects. Use of beta blockers resulted in the least improvement in QOL scores.

\section{KEYWORDS}

Hypertension, Quality of Life, Anti-Hypertensive.

HOW TO CITE THIS ARTICLE: Malhotra A, Mahajan A, Singh T, et al. A study of quality of life in patients with hypertension. J. Evolution Med. Dent. Sci. 2018;7(11):1337-1340, DOI: 10.14260/jemds/2018/304

\section{BACKGROUND}

Although, Quality of Life (QOL) is not a well-defined concept, it is usually thought of as the ability to function well in daily living as perceived by the individual and includes aspects of physical and psychological well-being, social and leisure activity and general life satisfaction.[1] Quality of Life end points that are related to health are increasingly being used to adjust measures of effectiveness for clinical decision making, resource allocation and to evaluate drugs in clinical trials of cancer, arthritis, heart failure and hypertension. ${ }^{[2]}$

Hypertension is a chronic medical condition with elevated systemic arterial blood pressure. Clinically, Hypertension might be defined as that level of blood pressure at which the institution of therapy reduces blood pressure related morbidity and mortality. ${ }^{[3]}$

The "Seventh Report of the Joint National Committee (JNC) on Prevention, Detection, Evaluation and Treatment of High Blood Pressure" provides a new guideline for hypertension prevention and management.[4]

'Financial or Other Competing Interest': None.

Submission 28-08-2017, Peer Review 27-02-2018,

Acceptance 05-03-2018, Published 12-03-2018.

Corresponding Author:

Anju Bhagtana,

\#101 PG Hostel,

$D M C H$,

Ludhiana, Punjab.

E-mail: anju_bhagtana@rediffmail.com

DOI: $10.14260 /$ jemds/2018/304

\section{(c) (i) $(2)$}

\section{MATERIALS AND METHODS \\ Design and Sampling \\ Design \\ Descriptive study.}

\section{Study Period \\ Two months.}

\section{Sampling}

All patients coming to the cardiac OPD of Hero DMC Heart Institute were taken as sample size.

\section{Sampling Procedure and Study Population}

All the consenting patients fulfilling the criteria were administered pre-validated Quality of Life Questionnaire (Appendix-1) and their responses were recorded.

All patients in the age group of 18 - 60 years who were drug naïve were included in the study. Pregnant, lactating or patients with various comorbidities like diabetes mellitus, ischaemic heart disease, kidney diseases, asthma and patients with complications of hypertension like stroke or myocardial infarction were excluded.

The socioeconomic status of the patient was calculated using the scale given by the Office of the Economic Advisor, Department of Industrial development, Ministry of Industries, Government of India.[5]

The presenting complaints were recorded in terms of 6month interval along with all the details. The past, personal and family history was recorded. The pulse was observed for one minute and rate, rhythm, character and symmetry was 
evaluated. The blood pressure was recorded in the right upper limb in sitting position. Average of three readings recorded was calculated.[6]

The prescribing physician chose the drug appropriate for the patient without any restriction. The patient was administered the Quality of Life Questionnaire (Appendix 1). The patient was followed up on subsequent visits. QOL Questionnaire was again administered after 6 weeks when the dosage got stabilised.

\section{Justification of Sample Size}

All patients coming to the Cardiac OPD in a period of two months and fulfilling the inclusion and exclusion criteria were taken up in the study.

Data was collected through patient interviews using questionnaires and clinical examination. Enrolled patients were interviewed. Interviews were conducted in local language. Initial pilot testing of the questionnaire was already done.

\section{Inclusion Criteria}

All patients in the age group of 18 - 60 years who were drug naïve.

\section{Exclusion Criteria}

Pregnant, lactating or patients with various comorbidities like diabetes mellitus, ischaemic heart disease, kidney disease, asthma and patients with complications of hypertension like stroke or myocardial infarction.

\section{Ethical Issues}

Ethical clearance was sought from Hospital Ethics Committee. Besides this-

1. Written consent was taken from patients participating in the study.

2. Confidentiality was maintained.

\section{Statistical Method}

Statistical analysis was performed by JASP graphical program for statistical analysis with Bayesian statistical methods. The data was analysed by using student's t-test paired was used to calculate the strength of association. A null hypothesis was formulated and ' $p$ ' value calculated with value of $<0.05$ was considered significant.

\section{RESULTS}

Maximum number of patients belonged to age group of 56 65 yrs. (42\%) followed by 46 - 55 yrs. (26\%), $26-35$ yrs. (20\%), $36-45$ yrs. (8\%) and $16-25$ yrs. (4\%). The prevalence of Hypertension in males (80\%) was quite high as compared to females (20\%). $56 \%$ of subjects belonged to urban population with majority belonging to upper-middle (78\%) group of socio-economic status followed by lowermiddle group (20\%) and least in upper-lower group (2\%). Among patients with hypertension highest percentage population was that of farmers $(30 \%)$ followed by servicemen (24\%), housewives (16\%), businessmen $(14 \%)$, retired population $(6 \%)$, unemployed $(6 \%)$ and students $(4 \%)$. Most of the patients presented with more than one complaint. Chest pain, dyspnoea on exertion and palpitations were the most common presenting complaints. Some of the patients were asymptomatic and were found to have increased BP during their regular health check-ups. Pain in left arm, insomnia, increased sweating, pedal oedema and orthopnoea were the less common presenting complaints. Family history was found to be significant in some patients. $14 \%$ patients had family history of Hypertension, $12 \%$ of Coronary Artery Disease and 4\% Diabetes Mellitus type2.

Along with the anti-hypertensives, adjuvants like hypolipidaemic drugs were prescribed to $24 \%$ patients, antianxiety to $8 \%$ patients and anti-platelet to $4 \%$ patients due to the presence of respective risk factors. Most significant reduction of pulse rate was with ACE inhibitors (Figure 1). All the antihypertensive drugs demonstrated a statistically significant reduction in SBP. Beta blockers $(p=0.0000001)$ showed the most significant decrease in mean SBP followed by ARB's, ACEI's, Diuretics and CCB's. All the antihypertensive drugs except diuretics demonstrated a statistically significant reduction in SBP. Beta blockers $(p=0.0000007)$ caused most significant decrease in mean diastolic BP followed by ARB's, ACEI's and CCB's (Figure 2). All the drugs demonstrated a reduction in mean pulse pressure. The most significant decrease in mean pulse pressure was seen with beta blockers ( $p=0.000007)$ followed by ACEI's, ARB's and diuretics. CCB's and diuretics did not show statistically significant decrease in mean pulse pressure (Figure 3). Thus, there was most significant reduction in mean of MAP with beta blockers ( $p=0.0000001$ ) followed by ARB's, ACEI's and CCB's.

Quality of life improved with all the antihypertensive drugs. The most significant improvement was seen with ARBs $(p=0.0004)$ followed by ACEI's, diuretics and beta blockers. But no significant improvement was observed with CCB's. (Figure 4). The Quality of Life was found to be low at the start of study (69.7 2.6). Marked improvement was observed in $90 \%$ of patients after 6 weeks (77.3 ? 2.3) of antihypertensive treatment (Figure 5).

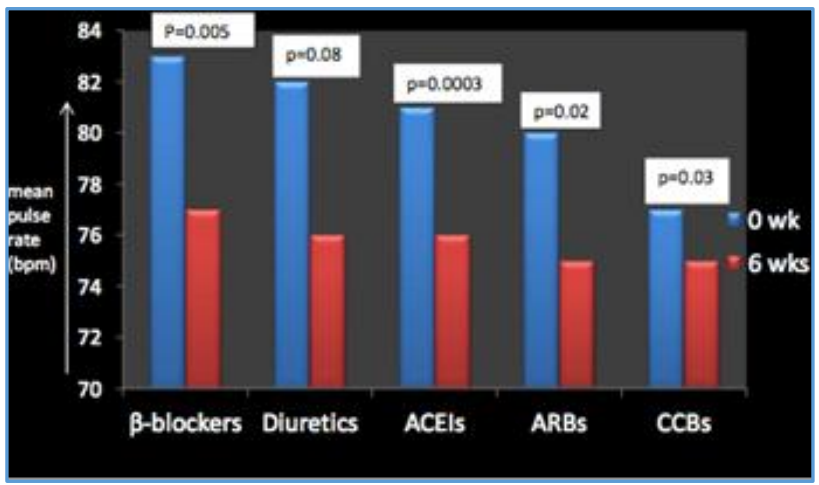

Figure 1. Figure depicting Mean Pulse Rate Variation

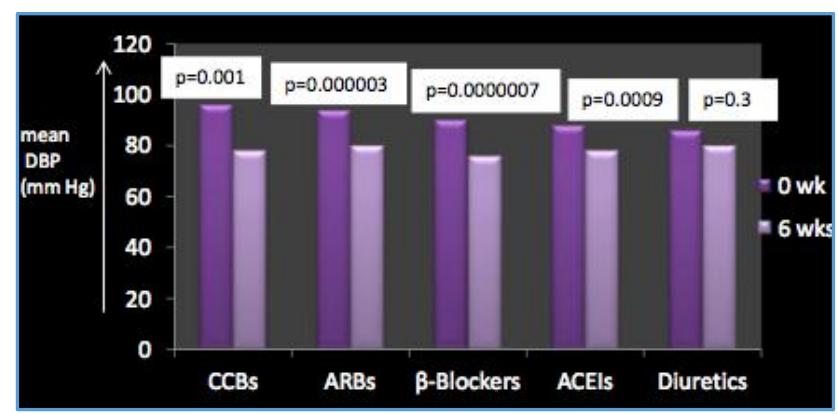

Figure 2. Figure depicting Mean DBP 


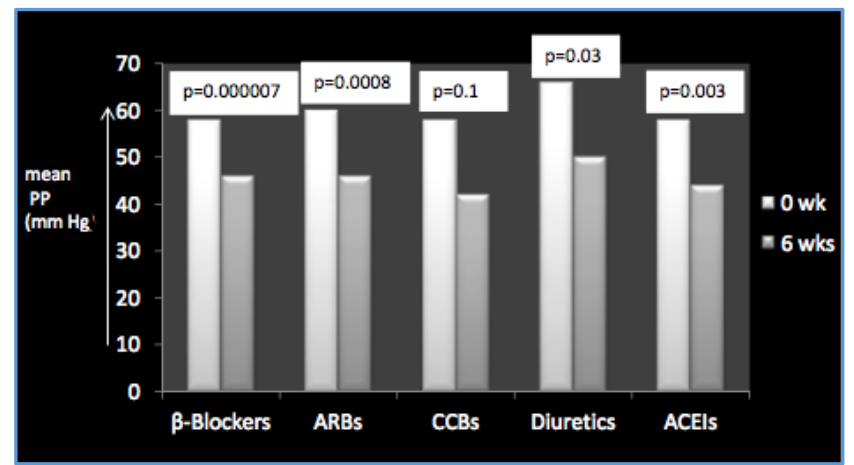

Figure 3. Figure depicting Pulse Pressure Variation

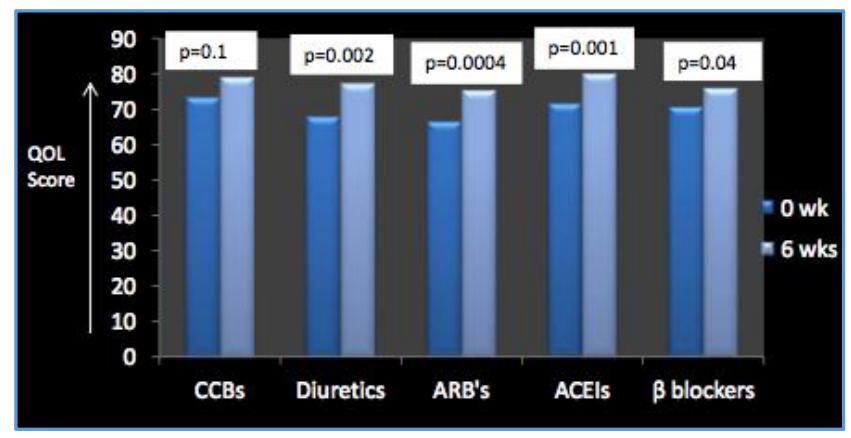

Figure 4. Variation in $Q O L$

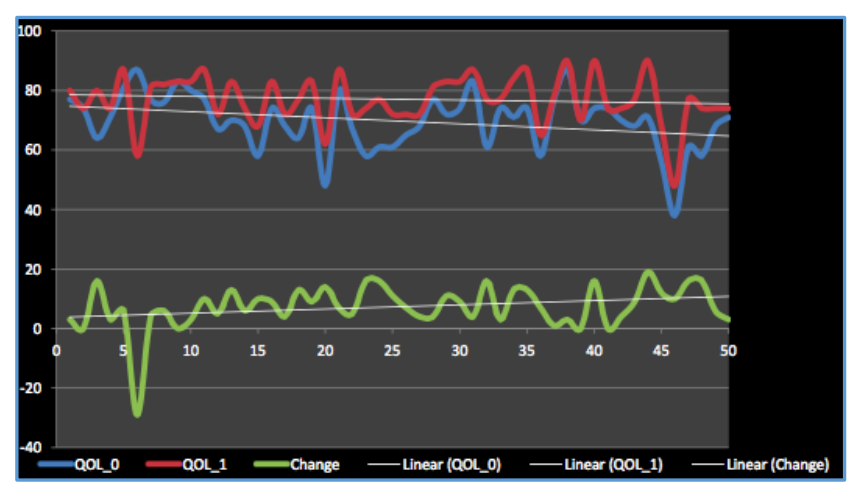

Figure 5. Figure depicting Percentage Change in QoL

\section{DISCUSSION}

Hypertension is commonly referred to as silent killer. Nonpharmacological and pharmacological therapy is required to control the BP in these patients.

A high prevalence of $69 \%$ and $55 \%$ was recorded among elderly populations aged sixty and above in the urban and rural areas respectively during 2000.[7] In 2002, Hazarika and co-workers reported $61 \%$ prevalence (Criteria: JNC VI) among men and women aged thirty and above in Assam. ${ }^{[8]}$ Majority of the patients in our study were in age group of 56 65 yrs. (42\%) followed by 46 - 55 yrs. (26\%). Thus, most of the studies show a higher incidence of hypertension among the elderly population. This implies that result of our study correlates with that of others. In our study, a slightly higher proportion of patients (56\%) were from urban background which could have been because of the Institution being a major medical centre in an industrial city, which is expanding very fast and surrounded by a large number of villages. Various studies have shown an increasing trend in incidence of the disease in both urban and rural population, but the prevalence is still definitely higher in urban population. $[9,10,11,12]$ Our study confirms the fact that hypertension is more common among a higher socioeconomic group as evidenced in various other studies as well.[13] Our study correlates with other studies establishing the fact that age, co-morbid conditions like diabetes and alcohol drinking are among the important risk factors for developing hypertension.[14] In the present study, family history of hypertension and various co-morbid conditions like CAD and DM was present in $30 \%$ patients pointing towards the genetic susceptibility. In our study, Quality of life improved significantly with ARB's $(p=0.0004)$ followed by ACEI's, diuretics and beta blockers. No significant improvement was observed with CCB's. Beta blockers was the drug used most commonly in spite of least improvement on QQL scores because of added advantage in other comorbid conditions like anxiety, angina and hyperthyroidism. In the present study higher incidence of hypertension is found to be among elderly, males, urban population, higher socioeconomic status and a significant improvement was observed in QOL with different anti-hypertensive agents. But these results need to be confirmed and verified in a large metacentric study.

\section{CONCLUSION}

In this six-week hospital-based study conducted among the recently diagnosed drug-naive patients with hypertension, it can be concluded that Hypertension was common in the agegroup of 56 - 65 years, male gender, belonging to upper middle class group, urban population. The most common presenting symptoms were chest pain, dyspnoea on exertion and palpitations. However, 28\% of these were asymptomatic at presentation. Among these patients, $26 \%$ had family history of hypertension or ischaemic heart disease. Additionally, $46 \%$ of these had history of substance abuse.

The most common antihypertensive drugs prescribed were beta-blockers, ARB's, ACEI's, Diuretics and CCB's. In addition, $36 \%$ of the patients were co-prescribed hypolipidaemic, anti-anxiety and anti-platelet agents based on their risk factor profile by the treating physician.

All the anti-hypertensive drugs produced a reduction in PR, SBP, DBP, PP and MAP at six weeks of therapy. The maximum reduction in pulse rate was produced by beta blockers and diuretics; that in SBP with CCB's and ARB's and in DBP with CCB's, ARB's and beta blockers. The use of antihypertensive drugs improved the QOL in $90 \%$ of study subjects. Use of beta blockers resulted in the least improvement in QOL scores and even deterioration in one subject. A large multicentric study would be needed to confirm the magnitude of improvement in QOL with the use of antihypertensive drugs in various states of Indian population, least improvement in QOL scores and even deterioration in one subject. A large multicentric study would be needed to confirm the magnitude of improvement in QOL with the use of antihypertensive drugs in various states of Indian population.

\section{REFERENCES}

[1] Grimm RH, Grandits GA, Cutler JA, et al. Relationships of quality-of-life measures to long-term lifestyle and drug treatment in the treatment of mild hypertension study. Arch Intern Med 1997;157(6):638-48. 
[2] Testa AM, Anderson RB, Nackley JF, et al. Quality of life hypertension study group. Quality of life and antihypertensive therapy in men. A comparison of captopril with enalapril. $\mathrm{N}$ Engl J Med 1993;328(13):907-13.

[3] Kotchen TA. Hypertensive vascular disease. In: Fauci AS, Kasper DL, Longo DL, et al. (eds). Harrison's principles of internal medicine. 17th edn. New York; McGraw Hill, 2008:1549-53.

[4] Hoffman BB. Therapy of hypertension. In: Brutan LL, Lazo JS, Parker KL. (eds). Goodman \& Gilman's The pharmacological basis of therapeutics. $11^{\text {th }}$ edn. New York; McGraw Hill, 2006:845-68.

[5] WHO-Project on sentinel surveillance of Indian Industrial population. ICMR Task force project on Collaborative study of coronary Heart Study.

[6] Timmis A. Cardiovascular system. In: Swash M, Glynn M. Hutchison's clinical methods. 22 ${ }^{\text {nd }}$ edn. Philadelphia; Saunders, 2007:76-7.

[7] Hypertension study group. Prevalence, Awareness, treatment and control of hypertension among elderly in Bangladesh and India: a multi centric study. Bull World Health Organ 2001;79(6):490-500.

[8] Hazarika NC, Biswas D, Narain K, et al. Hypertension and its risk factors in tea garden workers of Assam. Natl Med J India 2002;15(2):63-8.
[9] Dubey VD. A study on blood pressure amongst industrial workers of Kanpur. J Indiana State Med Assoc 1954;23(11):495-8.

[10] Wasir HS, Ramachandran P, Nath LM. Prevalence of hypertension in a closed urban community. Indian Heart J 1984;36(4):250-3.

[11] Chadha SL, Gopinath N, Shekhawat S. Urban-rural differences in the prevalence of coronary heart disease and its risk factors in Delhi. Bull World Health Organ 1997;75(1):31-8.

[12] Chadha SL, Radhakirshnan S, Ramachandran K, et al. Epidemiological study of coronary heart disease in urban population of Delhi. Indian J Med Res 1990;92:424-30.

[13] Mohan V, Shanthirani S, Deepa R, et al. Intra-urban differences in the prevalence of the metabolic syndrome in southern India--the Chennai Urban Population Study (CUPS No. 4). Diabet Med 2001;18(4):280-7.

[14] Wang W, Lee ET, Fabsitz RR, et al. A longitudinal study of hypertension risk factors and their relation to cardiovascular disease: the strong heart study. Hypertension 2006;47(3):403-9. 